\title{
Design and Fatigue Life Comparison of Steel and Composite Leaf Spring
}

\author{
Murathan Soner \\ Olgun Celik Company
}

Metin Tanoglu

Izmir Institute of Technology

Nilay Guven

Olguncelik Company

Mustafa Karaagac
Olgun Celik Company

Rasim Akyali, Ozay Aksoy, Tolga Erdogus, and Ahmet Kanbolat

Olguncelik Company

\begin{abstract}
It has been a significant challenge to reduce weights of the vehicles to satisfy the regulations that require development of environmentally-safe vehicles with low $\mathrm{CO} 2$ emissions. The conventional leaf springs, designed for the optimized performance together with safety factors, are made of steel. However, it is considered that the steel leaf springs are replaced by lighter ones in order to fulfill the specified requirements. Fiber reinforced composite materials with polymer based matrix offer a great potential for manufacturing leaf springs with lightweight, high mechanical and fatigue performance. Therefore, leaf spring manufacturers have great interest in those materials to replace steel parts with the composite ones and an increasing number of studies have been published in the literature in recent years. In this study, fiber reinforced composite compared with steel leaf springs based on endurance rig tests will be presented.
\end{abstract}

\section{INTRODUCTION}

Leaf spring systems are the important parts of the automobiles, which affect the weight of the vehicle in addition to driving performance and security. Seeking materials, which are lightweight and high performance, instead of steel has been continued in recent years and it has been accelerated in last few years all over the world due to recent regulations. Composite materials have the highest potential to become an alternative candidate material for this purpose. In addition to their lightweight, composite materials are suited to manufacture leaf springs due to their excellent fatigue performance, higher corrosion and chemical resistance and their process flexibility as compared to steel.

In automotive industry, composites reduce both the weight of the vehicle and the loads applied to the driver with it being in driving position. It is possible to manufacture products with design flexibility and high dimensional stability. Composite leaf springs are resistant to the vibrations at a higher frequency level in comparison with the metallic ones. They have high dielectric and corrosion resistance. It is possible to prevent composite leaf springs from exposing to rust and corrosion that generally occur on metal leaf springs. In addition to the monolithic ones, in recent years, researchers have been investigating the possibility to manufacture hybrid leaf springs with the combination of polymer-based composites and metals. It is also possible to 


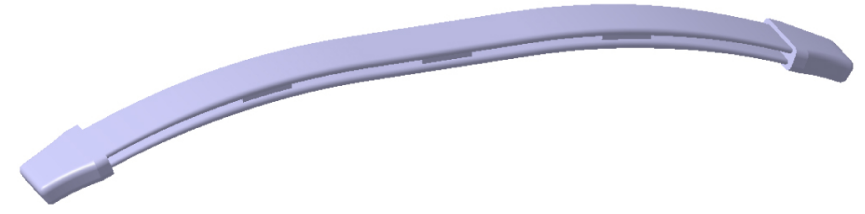

Figure 1. Cad model of anti-roll bar

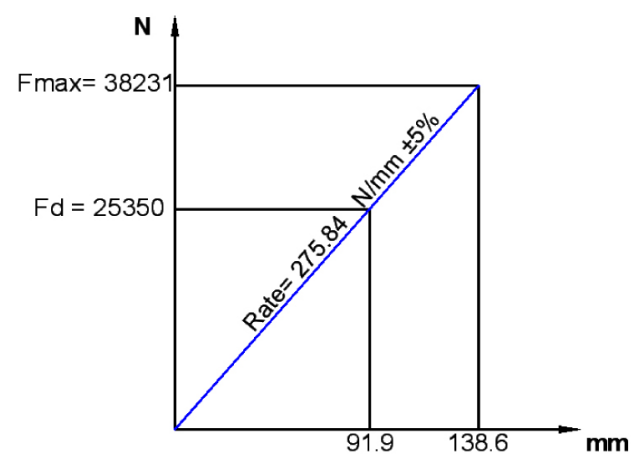

Figure 2. Load deflection diagram

produce high flame resistant composite parts by controlling the matrix content.

It is possible to provide the endurance for the leaf springs used in heavy vehicles by laying up the fiber in one direction. Under the dynamic working conditions of the leaf spring, force and moments at different axes with levels that should not be overlooked have an impact. For this reason, desired strength values are obtained by fiber reinforcement laid in two-ways and from different angles.

In this study, fiber reinforced polymer matrix composite leaf spring prototypes as an alternative to the steel leaf spring are developed. Analysis of stress within leaf springs under loading and obtaining selected optimum composite structures as a result of those analysis is the objective. Characterization of mechanical and endurance behavior of the selected composite and metal leaf spring structures is obtained.

\section{STEEL LEAF SPRING INPUTS}

The model, called as anti-roll bar, shown in Figure 1 and used in light commercial vehicles as steel leaf spring was designed by considering the load deflection diagram in Figure 2 . Target rate value in the load deflection diagram prevents the road frequency from entering in resonance with the vehicle resonance under dynamic working condition and improves the driver comfort. It is required to provide maximum 38231 $\mathrm{N}$ endurance that will have an impact on the leaf spring. It is possible for this model to ignore the twisting forces of lead springs due to their positions on the vehicle. The displacement values are lower in comparison with the parabolic leaf springs that are used together with on the same type of vehicles. In addition, it is considered that only vertical loads have an impact on it. Anti-roll bar specified as a model consists of 2 layers and its total length is $1300 \mathrm{~mm}$. Each layer has $100 \mathrm{~mm}$ width and $13 \mathrm{~mm}$ center thickness. Thickness decreases up to $9 \mathrm{~mm}$ towards the end of the leaf spring. Rubber silencers were inserted into gaps between the layers in order to make the proper operation of the layers. The two layered model weighs $26 \mathrm{kgs}$.

\section{STEEL LEAF SPRING FINITE ELEMENT ANALYSIS}

Stress analysis and rate control was carried out by using the finite elements analysis (FEA) in order to verify the design. Finite element analyses have been performed with Abaqus software. Hexagonal mesh was applied to the solid data of 2layer leaf spring. As mentioned in previous studies, it is necessary to use 4 elements at least while mesh is laid into the model. Rubber silencers were used for the proper operation of each leaf layer that overlaps. Isotropic material description was made for each leaf layer and rubber silencer. The following assignments are made for the spring, i.e. Spring: $\mathrm{E}=210,000 \mathrm{MPa}$, Poisson Ratio $=0.33$, Rubber Silencer: $\mathrm{E}=1000 \mathrm{MPa}$, Poisson Ratio $=0.475$. Friction constant of 0.02 was applied to leaf spring and rubber materials in order to analyze the model. Freedom was achieved for each horizontal direction of the leaf spring. The displacement distribution obtained due to the application of the load $(\mathrm{F}=38231 \mathrm{~N})$ with FEA is shown in Figure 3. Table 3 summarizes the displacement values and stress levels produced on the main leaf together with the identification of the locations. 

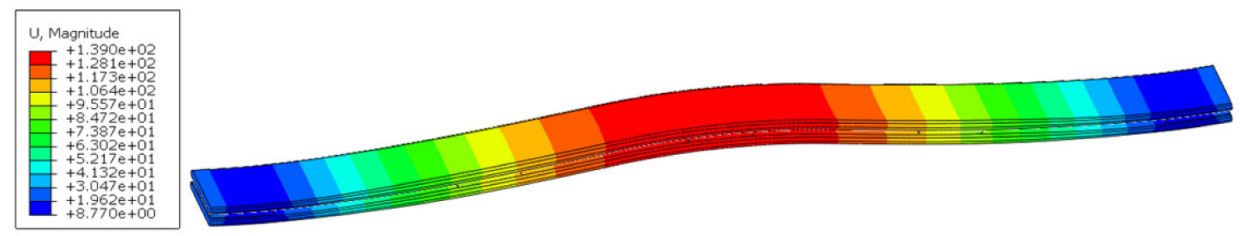

Figure 3. Finite element analysis result of the displacement distribution at F=38231 N on steel leaf spring.

Table 1. Displacement values and stress levels as a function of various positions on the steel leaf obtained with FEA.

\begin{tabular}{|c|c|c|c|c|c|}
\cline { 3 - 5 } \multicolumn{2}{c|}{} & \multicolumn{2}{c|}{ Fdesign = 25350 N } & \multicolumn{2}{c|}{ F max $=38231 \mathrm{~N}$} \\
\hline Main Leaf & $\begin{array}{c}\text { Position from } \\
\text { Centre (mm) }\end{array}$ & $\begin{array}{c}\text { Displacement of } \\
\text { Spring }\end{array}$ & $\begin{array}{c}\text { Stress } \\
\text { Value@Node }\end{array}$ & $\begin{array}{c}\text { Displacement of } \\
\text { Spring }\end{array}$ & $\begin{array}{c}\text { Stress Value @ } \\
\text { Node }\end{array}$ \\
\hline Element 1 & 210 & \multirow{4}{*}{$93 \mathrm{~mm}$} & $796 \mathrm{Mpa}$ & & $1160 \mathrm{Mpa}$ \\
\hline Element 2 & 405 & & $592 \mathrm{Mpa}$ & \multirow{2}{*}{$139 \mathrm{~mm}$} & $984 \mathrm{Mpa}$ \\
\hline Element 3 & 196 & \multirow{2}{*}{$930 \mathrm{Mpa}$} & & $1155 \mathrm{Mpa}$ \\
\hline Element 4 & 398 & & $580 \mathrm{Mpa}$ & & $980 \mathrm{Mpa}$ \\
\hline
\end{tabular}

Table 2. Strain gauge measurement result

\begin{tabular}{|c|c|c|c|c|c|}
\hline & & \multicolumn{2}{|c|}{ Fdesign $=25350 \mathrm{~N}$} & \multicolumn{2}{|c|}{$\mathrm{F} \max =38231 \mathrm{~N}$} \\
\hline Main Leaf & $\begin{array}{l}\text { Position from } \\
\text { Centre }(\mathrm{mm})\end{array}$ & Displacement & Stress Distribution & Displacement & Stress Distribution \\
\hline Front strain gauge 1 & 210 & \multirow{4}{*}{$90 \mathrm{~mm}$} & 752Mpa & \multirow{4}{*}{$136 \mathrm{~mm}$} & 1172Mpa \\
\hline Front strain gauge 2 & 405 & & 544Mpa & & 964Mpa \\
\hline Rear strain gauge 3 & 196 & & 767Mpa & & 1185Mpa \\
\hline Rear strain gauge 4 & 398 & & $561 \mathrm{Mpa}$ & & 968Mpa \\
\hline
\end{tabular}

\section{STEEL LEAF PROTOTYPE \& RIG TESTS}

Prototype of the leaf spring, whose design was verified by finite elements analysis, was produced as shown in Figure 4. Strain measurement of the leaf spring was performed by attachment of the strain gauges (Figure 5). Results of strain measurement are shown in Table 2.

The leaf spring produced as prototype was subjected to life test within the range of $\mathrm{F}$ max $=38231 \mathrm{~N}$ and $\mathrm{F} \min =42000$ $\mathrm{N}$, applying $3 / 4 \mathrm{~Hz}$ in vertical rig test (Figure 6 and 7) until breakage point. Leaf spring manufacturers shall ensure the endurance of their prototypes by conducting bad road tests in order to start mass production. Vertical rig test is one of the critical tests that must be carried out to verify the endurance of the prototype produced under the bad road conditions. Based on the previous experiences, it is known that the minimum 200000 vertical rig test cycles are required for such kind of leaf spring without producing any crack. The mentioned test continued until breakage occured on the prototypes. At least five specimens from each set was tested and the test results are shown at Table 3.

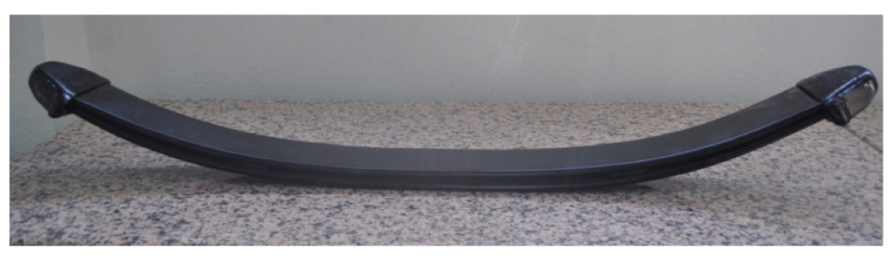

Figure 4. Steel spring prototype

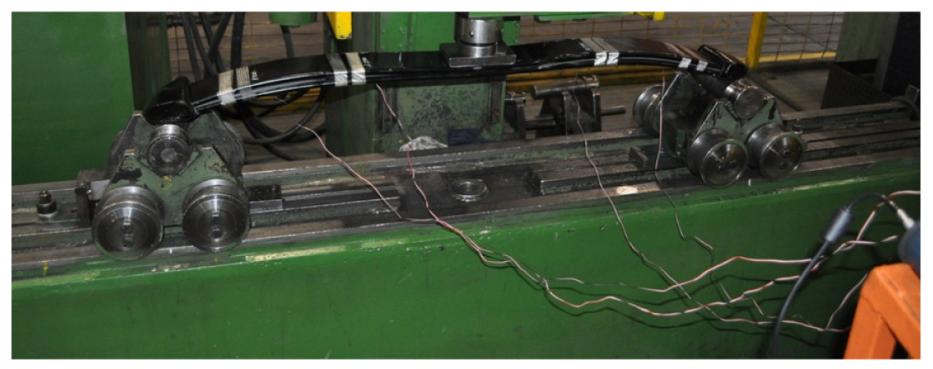

Figure 5. Steel leaf spring strain gauge measurement results

\section{COMPOSITE LEAF SPRING INPUTS}

The design of the composite leaf spring as mono layer was completed as an alternative to the steel leaf spring with two layers. The design of the composite leaf spring is illustrated in Figure 8. The composite leaf spring was designed in such a 


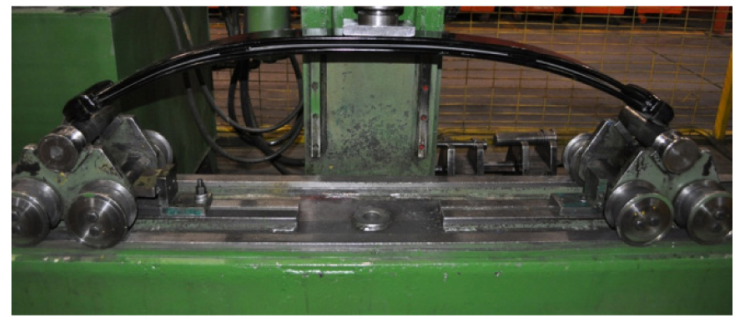

Figure 6. $F=0 \mathrm{~N}$ vertical rig test

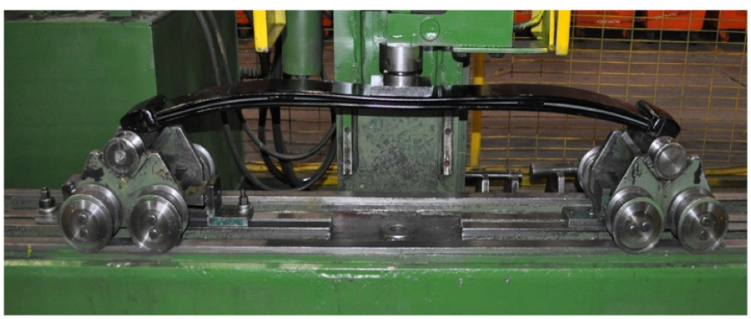

Figure 7. $F=38231 N$ vertical rig test

Table 3. Vertical rig test result

\begin{tabular}{|c|c|c|c|c|c|}
\hline Sample & $\begin{array}{c}\text { Required Rig Test } \\
\text { Cycle }\end{array}$ & Test Load Min. & Test Load Max. & Frequency & $\begin{array}{c}\text { Completed Rig } \\
\text { Test Cycle }\end{array}$ \\
\hline 1 & & & & 216.353 cycle \\
\hline 2 & \multirow{2}{*}{200.000 cycle } & $4200 \mathrm{~N}$ & $38231 \mathrm{~N}$ & 208.137 cycle \\
\hline 3 & & & $3 / 4 \mathrm{Hertz}$ & 213.941 cycle \\
\cline { 1 - 2 } & & & & 215.914 cycle \\
\hline 5 & & & 210.156 cycle \\
\hline
\end{tabular}

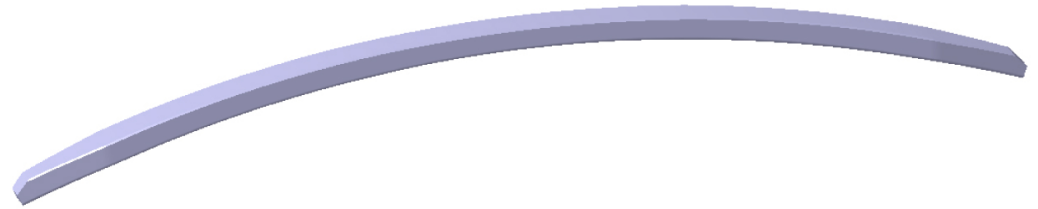

Figure 8. Composite spring computer aided design model

way that 1) it has the same rate values offering the same driving comfort with steel leaf spring and 2) providing higher fatigue strength. It is an advantage that the mono leaf structure without silencer creates low noise under various working conditions. The leaf spring designed has a weight of $5.2 \mathrm{~kg}$., $75 \mathrm{~mm}$ width and $29 \mathrm{~mm}$ thickness at the center area. The thickness is reduced by $20 \mathrm{~mm}$ towards the ends. Total length between the end axes of the leaf spring was designed as $1300 \mathrm{~mm}$ that equals to steel leaf spring.

\section{COMPOSITE LEAF SPRING FINITE ELEMENT ANALYSIS}

Stress analysis and rate control was carried out by using the finite elements analysis (FEA) in order to verify the design in the same way as those for the steel leaf spring. Due to the fact that composite structures are anisotropic materials, it is more difficult to identify the material structure as compared to metallic materials. The designed solid model was divided into six layers. In order to describe the materials in a correct way, the coupon samples of the material which were tested under different fiber orientations in pre-impregnated condition were taken. Material elastic constants of these samples $\left(\mathrm{E}_{1}, \mathrm{E}_{2}, \mathrm{v}_{12}, \mathrm{G}_{12}, \mathrm{G}_{13}\right.$ values) were assigned on the layers defined as lamina in Abaqus software. In this reference study, the following values are specified for the leaf spring material that is made of carbon fiber reinforced epoxy materials $\left(\mathrm{E}_{1}=\right.$ $228 \mathrm{GPa}, \mathrm{E}_{2}=31 \mathrm{GPa}, \mathrm{v}_{12}=0.2, \mathrm{G}_{12}=18 \mathrm{GPa}, \mathrm{G}_{23}=16.5 \mathrm{GPa}$ ).

The fact that the determination of solid part as continuum shell from created composite layup segment and 
Table 4. Composite spring $C A E$ von Mises results

\begin{tabular}{|c|c|c|c|c|c|}
\hline & & Fdesign & $=25350 \mathrm{~N}$ & $\mathrm{~F} \max =$ & $38231 \mathrm{~N}$ \\
\hline Main Leaf & $\begin{array}{l}\text { Position from } \\
\text { Centre }(\mathrm{mm})\end{array}$ & $\begin{array}{l}\text { Displacement of } \\
\text { Spring }\end{array}$ & Stress Value@Node & $\begin{array}{c}\text { Displacement of } \\
\text { Spring }\end{array}$ & $\begin{array}{c}\text { Stress Value @ } \\
\text { Node }\end{array}$ \\
\hline Element 1 & 210 & \multirow{4}{*}{$92 \mathrm{~mm}$} & 860Мра & \multirow{4}{*}{$139 \mathrm{~mm}$} & 1240Мра \\
\hline Element 2 & 405 & & $622 \mathrm{Mpa}$ & & 1012Mpa \\
\hline Element 3 & 196 & & 864Mpa & & 1234Mpa \\
\hline Element 4 & 398 & & 610Mpa & & 1025Mpa \\
\hline
\end{tabular}

Table 5. Carbon fiber based composite leaf spring strain gange measurement result

\begin{tabular}{|c|c|c|c|c|c|}
\hline & & \multicolumn{2}{|c|}{ Fdesign $=25350 \mathrm{~N}$} & \multicolumn{2}{|c|}{$\mathrm{F} \max =38231 \mathrm{~N}$} \\
\hline Main Leaf & $\begin{array}{l}\text { Position from } \\
\text { Centre (mm) }\end{array}$ & $\begin{array}{l}\text { Displacement of } \\
\text { Spring }\end{array}$ & $\begin{array}{c}\text { Stress } \\
\text { Value@Node }\end{array}$ & $\begin{array}{c}\text { Displacement of } \\
\text { Spring }\end{array}$ & $\begin{array}{c}\text { Stress Value @ } \\
\text { Node }\end{array}$ \\
\hline Front Strain Gauge 1 & 210 & \multirow{4}{*}{$94 \mathrm{~mm}$} & 884Mpa & \multirow{4}{*}{$140 \mathrm{~mm}$} & 1265Mpa \\
\hline Front Strain Gauge 2 & 405 & & 631Mpa & & 1108Mpa \\
\hline Front Strain Gauge 3 & 196 & & 868Мра & & 1284Mpa \\
\hline Front Strain Gauge 4 & 398 & & $652 \mathrm{Mpa}$ & & $1125 \mathrm{Mpa}$ \\
\hline
\end{tabular}

identification of layers as lamina and performing the fiber orientations from right angles are significantly important to obtain highly correlated results with real life. Other boundary conditions were inserted for the finite elements solution in similar way to the steel leaf spring.

Displacement values obtained from the FEA of composite leaf spring and stress levels occurred on the main leaf are presented in Table 4.

\section{COMPOSITE LEAF SPRING LEAF PROTOTYPE \& RIG TESTS}

Prototype of the single layered composite leaf spring, whose design was verified by FEA, was produced. High modulus (HM) unidirectional non-crimp carbon fabrics and epoxy thermosetting resin were used to fabricate composite leaf spring. DGEBA (Diglycidyl ether of bisphenol A) type epoxy resin together with an amine curing agent was used as the matrix. The composite panels were manufactured using Resin Transfers Molding (RTM) technique. In this technique, dry carbon fabrics were placed into a RTM mold cavity. After the placement of the fabrics, the mold was closed and clamped tightly, and then the resin was injected into the mold cavity. After completion of the resin injection and curing, the parts were demolded and transferred into an oven for post curing at $120^{\circ} \mathrm{C}$ for 2 hours. The fiber volume fraction values of the composites were measured based on common matrix burnout technique and found to be about $58 \%$.

Stress measurement and rate control of the carbon fiber based composite leaf spring was carried out by means of strain gauges as shown in Figure 9. The leaf spring produced as prototype was tested within the range of $\mathrm{F} \max =38231 \mathrm{~N}$ and $\mathrm{F}$ min $=42000 \mathrm{~N}$ by applying $3 / 4 \mathrm{~Hz}$ in vertical rig test (igure $\underline{10}$ and $\underline{11}$ ) until breakage occured.

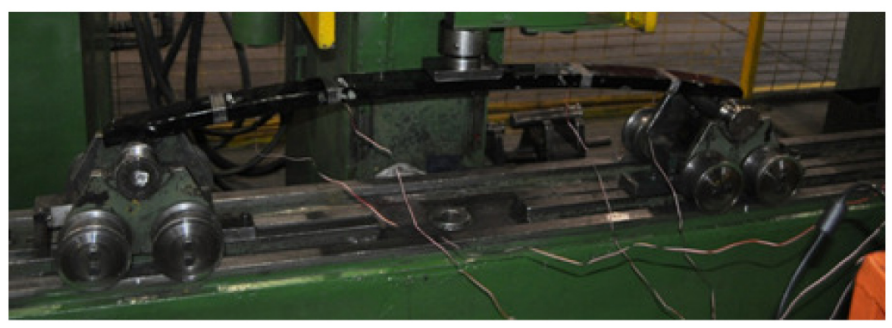

Figure 9. Carbon fiber based composite leaf spring strain gauge measurement

The leaf spring produced as prototype was operated within the range of $F$ max $=38231 \mathrm{~N}$ and $\mathrm{F}$ min $=42000 \mathrm{~N} 3 / 4$ Hertz in vertical rig test (Figure 10 - Figure 11) until breakage occurs.

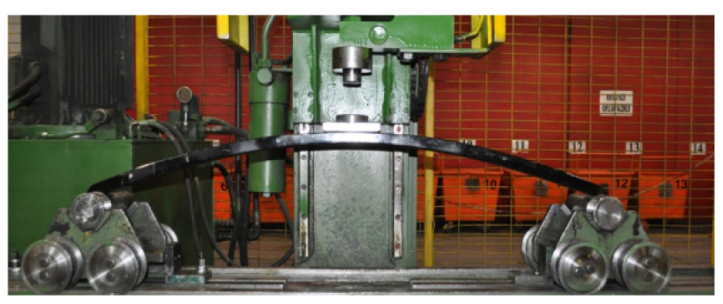

Figure 10. $F=0 \mathrm{~N}$ vertical rig test

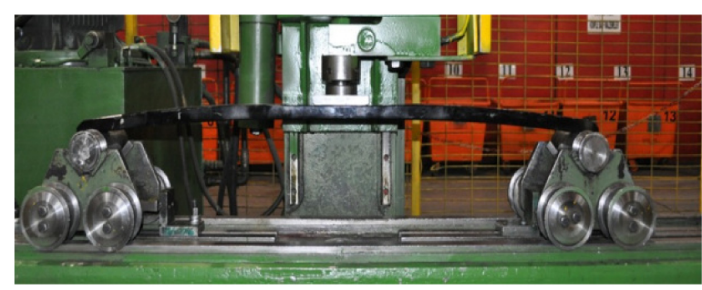

Figure 11. $F=38231 N$ vertical rig test 
As a result of vertical rig test, the composite leaf spring fractured after 342125 cycles which is far above the required 200000 cycles.

As an alternative for a lighter vehicle, composite leaf spring prototype with mono leaf was also produced by glass fiber reinforced epoxy composite material as shown in Figures 12 Figure 13. Glass fiber reinforced epoxy composite was designed and manufactured similar with those for the carbon fiber based composites. It was observed that the glass fiber reinforced epoxy also fully satisfied the requirements prescribed for the vehicle tests of leaf springs.

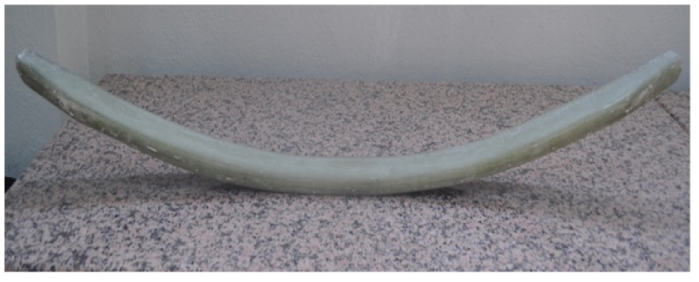

Figure 12. Glass fiber reinforced leaf spring

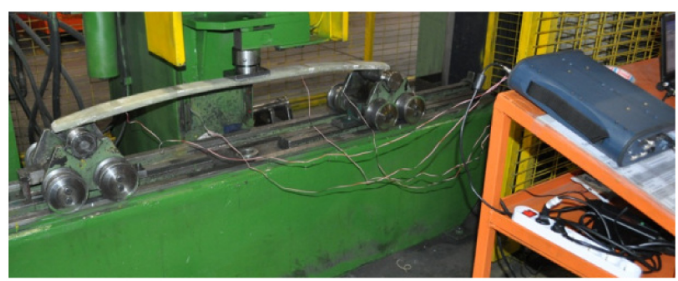

Figure 13. Glass fiber reinforced leaf spring under loading

\section{CONCLUSIONS}

High performance composite materials reinforced by long fibers of carbon show better fatigue behavior as compared to those with steel and glass fiber reinforced epoxy materials for the leaf springs. Endurance strength of composite materials subjected to cyclic tensile loading is greater than spring material. Endurance strength of composite differs based on the arrangement type of epoxy resin and fibers. However, it is known that the composites made of unidirectional fibers have lower strength in transverse direction. While carbon fibers show greater performance in comparison to glass fibers, on the other hand, glass fibers are highly economical. Therefore, the proper design optimization during the design phase of the product is highly effective to reduce the costs in material selection. As compared with steel, carbon fiber composite achieves about $80 \%$ material savings.
Fatigue behavior of composites may vary depending on additional operations such as delamination, transverse crack, debonding, drilling and other damage mechanisms.

Pre-impregnated composite fibers for the leaf spring composite production bring considerable advantage in order to provide lots of ranges and to accelerate the production process. Despite of the fact that it seems very expensive, the companies that are able to produce their own prepregs may take advantage in terms of cost and expenses. RTM is a cost effective process, but it may require some additional controls to provide stability in mass production process. Although some operational problems arise for obtaining parabolic structure in filament winding technology, it is distinguished from the others as the fastest production technique for a leaf spring with fixed thickness.

As summarized above, it is possible for designers to reduce the costs of prototype with virtual prototype process by using the finite elements analysis whose correlation is very close to real life.

\section{REFERENCES}

1. "Manual on Design and Application of Leaf Springs," SAE International, Warrendale, PA, ISBN 978-0-89883-383-6, 1980.

2. Mechanics of Composite Structure George S. Springer Stanford University.

3. Structural and Stress Analysis Dr. T.H.G Megson

\section{CONTACT INFORMATION}

Murathan Soner

OlgunCelik

Cumhuriyet Bulvarı Organize Sanayi Bölgesi 45030 Manisa /

Turkey

murathansoner@olguncelik.com.tr

\section{DEFINITIONS/ABBREVIATIONS}

\section{CAD}

Computer Aided Design

CAE Computer Aided Engineering 
The Engineering Meetings Board has approved this paper for publication. It has successfully completed SAE's peer review process under the supervision of the session organizer. This process requires a minimum of three (3) reviews by industry experts.

All rights reserved. No part of this publication may be reproduced, stored in a retrieval system, or transmitted, in any form or by any means, electronic, mechanical, photocopying, recording, or otherwise, without the prior written permission of SAE. ISSN 0148-7191
Positions and opinions advanced in this paper are those of the author(s) and not necessarily those of SAE. The author is solely responsible for the content of the paper.

SAE Customer Service:

Tel: 877-606-7323 (inside USA and Canada)

Tel: 724-776-4970 (outside USA)

Fax: 724-776-0790

Email: CustomerService@sae.org

SAE Web Address: http://www.sae.org

Printed in USA 